\title{
Rupture uterus: a one year review to find out the causative factors
}

\author{
Beena Gupta ${ }^{1}$, Prabhat Kumar Bhagat ${ }^{2 *}$, Rezaul Karim ${ }^{2}$
}

\begin{abstract}
${ }^{1}$ Department of Obstetrics and Gynecology, Mata Gujri Memorial Medical College and Lions Seva Kendra Hospital, Kishanganj, Bihar, India

${ }^{2}$ Department of Radiodiagnosis, Mata Gujri Memorial Medical College and Lions Seva Kendra Hospital, Kishanganj, Bihar, India
\end{abstract}

Received: 22 May 2020

Accepted: 30 June 2020

\section{*Correspondence:}

Dr. Prabhat Kumar Bhagat,

E-mail: pbbhagat21@gmail.com

Copyright: (C) the author(s), publisher and licensee Medip Academy. This is an open-access article distributed under the terms of the Creative Commons Attribution Non-Commercial License, which permits unrestricted non-commercial use, distribution, and reproduction in any medium, provided the original work is properly cited.

\begin{abstract}
Background: Rupture uterus is a life-threatening obstetric emergency associated with high perinatal mortality. This study aims to find out the common factors associated with this catastrophic condition so as to help in decreasing the incidence of this condition in this study set-up. The objective of this study was to determine incidence, sociodemographic factors, etiology, types of presentation, patterns of management and maternal and fetal outcome in cases of rupture uterus presenting in this study hospital in one year.

Methods: In this retrospective study 40 cases of ruptured uterus admitted in the hospital between January to December 2016 were analyzed. Detailed history of relevant socio-demographic factors, prior obstetric and surgical history, clinical findings, nature of management done, fetal and maternal outcome were thoroughly analyzed from the record.

Results: A total 40 cases of ruptured uterus during this one-year period out of total 1220 deliveries constituted an incidence of $3 \%$. The commonest age group is $25-30$ years (47\%). Majority of patients of rupture uterus were those with previous scarred uterus trying for vaginal delivery in hands of dais, untrained birth attendants and midwives. Repair was possible in the majority of cases. There were no maternal deaths but fetal mortality was $92.5 \%$.

Conclusions: Proper antenatal care, transportation facilities, good counseling of patients with history of previous uterine surgery for institutional delivery can help in reducing the incidence of rupture uterus in developing countries like India. Prompt surgical intervention can help in reducing the maternal morbidity and mortality associated with rupture uterus.
\end{abstract}

Keywords: Maternal mortality, Multipara, Rupture uterus, Uterine scar

\section{INTRODUCTION}

Uterine rupture is one of the major causes of obstetric hemorrhage. This emergency and catastrophic condition if not managed promptly leads to severe maternal and perinatal morbidity and mortality. This grave condition accounts for about $9.3 \%$ of maternal deaths and is almost fatal for fetus. ${ }^{1}$

Uterine rupture may be primary, defined as occurring in previously intact or unscarred uterus, or may be secondary and is associated with pre-existing myometrial incision, injury or anomaly. ${ }^{2}$

Uterine rupture is also classified as either complete when all layers of uterine wall are separated or incomplete when uterine muscle is separated but visceral peritoneum is intact (also called uterine dehiscence). ${ }^{3}$

Common causes associated with uterine rupture are previous caesarean section or hysterotomy, previously repaired uterine rupture, myomectomy through or to the 
endometrium, metroplasty and other operations which traumatize the myometrium like uterine curettage or perforation, endometrial ablation etc. ${ }^{2}$

In our country a number of socio-demographic factors like lack of health education, early marriage, lack of proper health facilities, poor quality of antenatal checkup, delivery by untrained dais etc. are responsible for the high incidence of uterine rupture. Patients are brought to the hospital after prolonged delay when untrained daises fail to deliver them, result being uterine rupture. ${ }^{4}$ Uterine rupture during pregnancy is a rare occurrence whereas uterine scar dehiscence is a more common event. ${ }^{5}$

This retrospective study aims to determine the incidence, common etiologies, trend, management, maternal and fetal outcome to identify the measures needed to prevent/decrease the incidence of rupture uterus and thus maternal and perinatal mortality and morbidity.

\section{METHODS}

This is a retrospective study of women with ruptured uterus from period January 2016 to December 2016 admitted in a tertiary care center.

Total number of hospital deliveries during this period was 1220.

\section{Inclusion criteria}

- All the cases of ruptured uterus who were admitted in this hospital during this period were included in study.

Admitted patients were assessed, relevant sociodemographic data, previous antenatal obstetric history, period of gestation, previous surgical history, duration of labour pain, previous treatment history were recorded.

The location of rupture, cause, type of surgery, maternal and fetal outcome were recorded. All patients were followed-up until their discharge from hospital and thereafter.

\section{RESULTS}

A total of 40 cases of rupture uterus were recorded from January 2016 to December 2016 constituting an incidence of $3 \%$. Age of patients ranged from 20-40 years. $19(47 \%)$ patients were in age group of $25-30$ years (Table 1).

Majority of rupture uterus occurred in patients with parity 1 and parity $2(45 \%)$ which depicts increase incidence of rupture in patients with previous scar on uterus (Table 2).

Table 3 shows that uterine rupture may occur any time from the beginning of third trimester of pregnancy but mostly occur at or near the term.
Table 1: Age distribution of patients.

\begin{tabular}{|lll|}
\hline Age group & No. of patients & $\%$ of total $(n=40)$ \\
\hline $20-25$ years & 6 & $15 \%$ \\
\hline $25-30$ years & 19 & $47 \%$ \\
\hline $30-35$ years & 10 & $25 \%$ \\
\hline $35-40$ years & 5 & $12.5 \%$ \\
\hline
\end{tabular}

Table 2: Distribution of parity.

\begin{tabular}{|lll|}
\hline Parity & No. of patients & $\%$ of total \\
\hline 1 & 11 & $27.5 \%$ \\
\hline 2 & 11 & $27.5 \%$ \\
\hline 3 & 6 & $15 \%$ \\
\hline 4 & 5 & $12.5 \%$ \\
\hline 5 & 7 & $17.5 \%$ \\
\hline
\end{tabular}

Table 3: Gestational age of patients.

\begin{tabular}{|lll|}
\hline Gestational age & No. of patients & $\%$ of total \\
\hline $28-32$ weeks & 2 & $5 \%$ \\
\hline $33-36$ weeks & 3 & $7.5 \%$ \\
\hline $37-40$ weeks & 25 & $62.5 \%$ \\
\hline$>40$ weeks & 10 & $25 \%$ \\
\hline
\end{tabular}

Majority of patients had no antenatal check-up (62.5\%) and $25 \%$ had irregular antenatal check-up (Table 4). $12.5 \%$ had regular antenatal check-up but did not turn up in hospital for delivery and took trial of delivery in hands of dais.

Table 4: Pattern of antenatal care.

\begin{tabular}{|lll|}
\hline Antenatal care & No. of patients & $\%$ of total \\
\hline No check-up & 25 & $62.5 \%$ \\
\hline Irregular check-up & 10 & $25 \%$ \\
\hline Regular check-up & 5 & $12.5 \%$ \\
\hline
\end{tabular}

Majority of patients were illiterate $(80 \%)$. Primary level of education was found among $(20 \%)$. None of the patients received secondary and higher education. Most of the patients came from remote villages (95\%) and rest from urban area.

Table 5: Etiology of rupture uterus.

\begin{tabular}{|l|ll|}
\hline Causes & Scarred & Unscarred \\
\hline Obstructed labour & $4(10 \%)$ & $5(12.5 \%)$ \\
\hline Dai handled & $22(55 \%)$ & $8(20 \%)$ \\
\hline Others & & $1(2.5 \%)$ \\
\hline
\end{tabular}

From Table 5, it appears that majority of rupture occurred in scarred uterus $(65 \%)$ and trial of labor by untrained dais and injudicious use of oxytocic $(55 \%)$ turned out to be the most important causative factor.

Majority of rupture occurred in previous scar 18 (45\%). Of this 5 were previous classical scar, 1 was inverted T 
Scar and 1 was rupture in previous two lower segment caesarean section (LSCS) scar. Rest was in previous single LSCS scar. In $6(15 \%)$ rupture was confined to lower segment. In $6(15 \%)$ rupture extended to upper and lateral segment of uterus. In $5(12.5 \%)$ there was injury to urinary bladder. In $4(10 \%)$ it was posterior uterine wall rupture. 1case was of cornual rupture (Table 6).

\section{Table 6: Site of rupture.}

\begin{tabular}{|lll|}
\hline Site of rupture & Number & Percentage \\
\hline Scar (all included) & 18 & $45 \%$ \\
\hline Lower segment & 6 & $15 \%$ \\
\hline $\begin{array}{l}\text { Extension to upper and } \\
\text { lateral segment }\end{array}$ & 6 & $15 \%$ \\
\hline Associated injury to bladder & 5 & $12.5 \%$ \\
\hline Posterior uterine wall & 4 & $10 \%$ \\
\hline Cornual rupture & 1 & $2.5 \%$ \\
\hline
\end{tabular}

Majority of patients $28(70 \%)$ underwent repair of rupture. In $10(25 \%)$ cases subtotal hysterectomy and in 2 (5\%) patients total hysterectomy had to be done. None of the patients died due to rupture or during surgical management. 5 patients needed repair of urinary bladder.

A total $36(90 \%)$ foetuses died intra-uterine, 1 (2.5\%) was still birth and $3(7.5 \%)$ were born with low Apgar score. All patients needed blood transfusion, broad spectrum antibiotics and ICU management. Average duration of stay was 8-15 days.

\section{DISCUSSION}

Rupture of gravid uterus is one of the most serious obstetric emergencies with several adverse fetal and maternal health consequences. ${ }^{6}$

The incidence of one in 30 deliveries (3\%) of uterine rupture in this series is very high as compared to similar studies done in past by Alam et al who reported a figure of $1.14 \% .^{7}$ This high rate is similar to that of Ethiopia $2.8 \%{ }^{8}$ Studies from developed countries showed incidences recorded as $0.035 \% .^{9}$ Lack of health consciousness, illiteracy, poor antenatal care, poverty, home delivery by traditional birth attendant are some of the relevant social factors that contribute to uterine rupture in developing countries. This high incidence of uterine rupture in this set-up depicts that majority of patients admitted in this hospital are high risk and are referred to this study hospital after taking trial in hands of dais or untrained birth attendants. Studies conducted in developing countries gives strong evidence that uterine rupture is a major health problem in developing countries with the rate higher in rural areas. ${ }^{10}$ However, many efforts in developing countries have proven insufficient and ineffective in reducing maternal mortality in general because the issue is viewed as medical or clinical dilemma rather than a broader public health problem. According to WHO exploring factors which are beyond the biomedical causes will have essential implication for preventive programs in developing countries. ${ }^{11}$

Majority of patients in this study belonged to age group of 25-30 years (47\%) which was similar to study done by Sunita et al $(50 \%) .{ }^{12}$ But in the study done by khan et al most of cases occurred in age group of 31-35 years (47\%). ${ }^{13}$ This difference may be due to high incidence of early marriage and short inter-conception period in this patients.

Majority of rupture happened in parity 1 and parity 2 (45\%) which depicts increase incidence in patients with previous scarred uterus. ${ }^{14}$

Most of the patients were without or with irregular antenatal checkup (87.5\%) and most of them were illiterate which was similar to many other studies.

This retrospective study confirmed important risk factors for uterine rupture which included prior cesarean section, obstructed labor, inappropriate trial and use of oxytocin in malposition of the fetus (dai handled) which constituted $90 \%$ of the cases of rupture in this study. $65 \%$ of cases of rupture (most common) in this study was attributed to history of previous scarred uterus which was similar to study done by Mahbuba et al, (46.66\%). ${ }^{15}$ Hence intense supervision is required in managing patients with previous cesarean section who are willing for trial of labor. Such patients should be counseled about consequences of trial of labor and advised to come to hospital for safe delivery and not to take trial in hands of dais. In hospital also repeat cesarean delivery should be strongly considered if patients Freidman labor curve deviates from normal. Hamilton et al, reported that with labor dystocia (i.e. cervical dilatation lower than 10th percentile and arrest for more than 2 hours), cesarean section prevents $>42.1 \%$ cases of uterine rupture. ${ }^{16}$

The incidence of rupture differs depending on type of prior incision on uterus (low transverse, low vertical, classical T-shaped or unknown). Given the circumstances surrounding the previous delivery obstetrician should try to infer which type of uterine incision is most likely to present in any patient.

The consequences of uterine rupture depend on duration of time that has elapsed from occurrence of rupture until definitive management. Prompt supportive and resuscitative measures should be undertaken to prevent catastrophic consequences. Prompt Surgical intervention is required. The type of surgical intervention depends on type, location and extent of uterine rupture. In this study repair was possible in $70 \%$ of cases. However, repair increases the chance of uterine rupture in subsequent pregnancies, hence elective repeat cesarean delivery should be done in this group of patients.

In this study no maternal mortality occurred after rupture which was similar to many other studies. This depicts that 
with prompt diagnosis and definitive surgical management, maternal mortality can be reduced to zero. The main causes of maternal mortality in rupture uterus are failure to diagnose the condition at first referral center and arrival at tertiary center in a moribund condition. ${ }^{17}$

Majority of fetus $(90 \%)$ in this study were intra uterine death which happened because majority (97.5\%) of patients in this study had no antenatal care and were transferred to the hospital after long delay after taking trial of labor in home by dais or because of lack of adequate transportation facilities.

\section{CONCLUSION}

The causes of uterine rupture are complex with a number of factors like medical, reproductive, health services, nutritional and socio-economic playing the major role.

Illiteracy, early marriage, poor socioeconomic conditions, ignorance, poor medical and antenatal facilities in rural areas, inappropriate counselling of patients with scarred uterus for hospital delivery, poor transportation facilities, dai handling, inappropriate use of oxytocic's, delay in seeking management are most common causes of rupture uterus in this study.

Hence to decrease the incidence of rupture uterus in this set-up and in general in developing countries like India, many steps have to be taken at the basic level like general improvement in socioeconomic conditions, better health services in rural areas, proper training of birth attendants, improvement in transportation facilities. Improving the education level of the population would greatly help in decreasing this problem.

Funding: No funding sources Conflict of interest: None declared

Ethical approval: Not required

\section{REFERENCES}

1. Rajaram P, Agarwal A, Swain S. Determinants of maternal mortality: a hospital-based study from South India. Indian J Matern Child Health. 1995;6(1):7-10.

2. Cunningham F. In Obstetrical hemorrhageand prior caesarean delivery, Cunningham FG, Leveno KJ, Bloom SL, Spong CY et al (eds.), William's Obstetrics, 24 $4^{\text {th }}$ ed, by McGraw-Hill Education; 2014;790-793: 609-20.

3. Cunningham FG, MacDonald PC, Gant NF. Obstetrical hemorrhage. Williams Obstetrics. Stamford Conn, Appleton and Lange, $20^{\text {th }}$ ed; 1997: $772-778$.
4. Malik HS. Frequency, predisposing factors and fetomaternal outcome in uterine rupture. J Coll Physicians Surg Pak. 2006;16:472-5.

5. Bashin A, Burstein E, Rosen S, Smolin A, Shiner E, Mazor M. Clinical Significance of uterine scar dehiscence in women with previous caesarean delivery: Prevalence and independent risk factors. J Reprod Med. 2008; 53:8-14.

6. Eden RD, Parker RT, Gall SA. Rupture of the pregnant uterus: a 53- year review. Obstet Gynecol. 1986;68(5):671-4.

7. Alam I, Khan A, Ahmed R, Begum N. A tow year review of uterine rupture at gynaecology unit-a ayub teaching hospital. J Ayub Med Coll Abottabad. 2000;12:21-2.

8. Omole-Ohonsi A, Attah R. Risk factors for ruptured uterus in a developing country. Gynecol Obstet. 2011;1(102):2161-0932.

9. Ofir K, Sheiner E, Levy A, Katz M, Mazor M. Uterine rupture: differences between a scarred and an unscarred uterus. Am J Obstet Gynecol. 2004;191(2):425-9.

10. UNICEF. The state of the World's Children Report Oxford University, Press New York; 1996.

11. WHO. Health status statistics: mortality. Geneva: World Health Organization; 2013.

12. Sunitha K, Indira I, Suguna P. Clinical study of rupture uterus - assessment of maternal and fetal outcome. IOSR-JDMS. 2015;14(3):39-45.

13. Khan S, Parveen Z, Begum S, Alam I. Uterine rupture: a review of 34 cases at Ayub Teaching Hospital Abbottabad. J Ayub Med Coll Abottabad. 2003;15:50-2.

14. Tayab S. Rupture of gravid uterus still an obstetrical problem. A three-year clinical analysis. J Coll Physician Surg Pak. 1996;6:144-7.

15. Mahbuba, Alam IP. Uterine rupture - experience of 30 cases at Faridpur Medical College Hospital. Faridpur Med Coll J. 2012;7(2):79-81.

16. Hamilton EF, Bujold E, McNamara H, Gauthier R, Platt RW. Dystocia among women with symptomatic uterine rupture. Am J Obstet Gynecol. 2001;184:620-4.

17. Ofir K, Sheiner E, Levy A, Katz M, Mazor M. Uterine rupture: differences between a scarred and an unscarred uterus. Am J Obstet Gynecol. 2004;191(2):425-9.

Cite this article as: Gupta B, Bhagat PK, Karim R. Rupture uterus: a one year review to find out the causative factors. Int J Reprod Contracept Obstet Gynecol 2020;9:3249-52. 